\title{
REFERENCES
}

1. Drannikova O. About playing nature of scherzo in the symphony of the XIX century: historical-culturological aspect. Retrieved fromhttp://journalpmn.com/ index.php /PMN/article/viewFile/400/394 [in Russian].

2. LyahinaT. (2009) Fantasy in violin music XIX century, Scientific journal of the Ukraine National P. I. Tchaikovsky academy of music. (issue 82), (pp. 69-79). Kyiv [in Ukraine].

3. Malzev S. (1991) About psychology of musical improvisation. Moscow: Muzyika [in Russian].

4. Usov Y. (1989) History of the foreign carrying out on wind instruments. Moscow: Muzyika [in Russian].

5. Yampolsky I. (1955) Genrih Venyavsky. Moscow: Musgiz [in Russian].

6. Zoboli Omar. Antonio Pasculli. Grand Concerto. Staatliche Hochschule fur Musik-Bibliothek. XIIak. 330. № 88 [in German].

Стаття надійшла до редакції 28.06.2017

УДК 78.01+782/785.7+78.07.1＜noBreak> DOI: 10.31723/2524-0447-2017-25-42-53

Анатолий Валентинович Носуля

https://orcid.org/0000-0002-3003-6472

кандидат искусствоведения, в.о. доцента

кафедры сольного пения

ОНМА имени А. В. Неждановой

odma_n@ukr.net

\section{ГЕНЕЗИС И ЖАНРОВЫЕ АТРИБУТЫ КАМЕРНОЙ ОПЕРЫ}

Целью статьи является исследование генезиса камерной оперы на пути формирования ее типологических признаков и возникновения различных жсанровых модификаций. Научная новизна обусловлена выявлением и обоснованием типологических черт, характерных особенностей жанровой сферы камерной оперы. Методология. В статье применяется обновленный аналитический подход в изучении европейских камерных опер, на основании которого становится возможным определять жанровые атрибуты и характерные особенности композиторского стилистического комплекса. Выводы. С конца ХІХ века, камерная опера приобретает самостоятельность, отделяясь от иных разновидностей оперного жанра, становится равноправной единицей, сохраняя и упрочивая этот статус вплоть до сегодняшних дней. Наиболее показательными чертами камернизации оперного жанра можно назвать его психологическую направленность со стремлением передать сложный и противоречивый

(C) Носуля А. В., 2017 
внутренний мир героев оперного произведения. Зачастую композиторы создают концепцию рефлексирующего человека и ощущение противостояния личности окружающему миру.

Ключевые слова: опера, жанр, камерная опера, камернизация, драматургическое содержание, «новая драма».

Nosulya Anatoly, Ph.D. in History of Arts, Associate Professor of Department of Solo Singing of Odessa National A. V. Nezhdanova Academy of Music

Genesis and genre attributes of the chamber opera

The purpose of this article is to study the genesis of the chamber opera on the way of the formation of its typological features and the genesis of various genre modifications. Scientific novelty due to the identification and justification of typological features, characteristic features of the genre sphere of chamber opera. Methodology. The article uses an updated analytical approach to the study of European chamber operas, on the basis of which it becomes possible to determine the genre attributes and characteristics of the composer's stylistic complex. Conclusions. Starting from the end of the 19th century, the chamber opera acquires independence, being separated from other varieties of the operatic genre, becoming an equal unit, maintaining and strengthening this status right up to the present day. The most illustrative features of the operatic genre of operatic are its psychological orientation with the desire to convey the complex and controversial inner world of the heroes of operatic work. Often, composers create the concept of a reflective person and a sense of opposition to the outside world.

Keywords: opera, genre, chamber opera, chamberization, dramatic content, «new drama».

Носуля Анатолій Валентинович, кандидат мистецтвознавства, в.о. доцента кафедри сольного співу ОНМА імені А. В. Нежданової

\section{Генезис та жанрові атрибути камерної опери}

Метою статті є дослідження генези камерної опери на шляху формування ї̈ типологічних ознак й виникнення різних жанрових модифікацій. Наукова новизна обумовлена виявленням та обтрунтуванням типологічних рис, характерних особливостей жанрової сфери камерної опери. Методологія. У статті застосовується оновлений аналітичний підхід до вивчення європейських камерних опер, на підставі якого стає можливим визначати жсанрові атрибути та характерні особливості композиторського стилістичного комплексу. Висновки. 3 кіния ХІХ століття, камерна опера набуває самостійність, відділяючись від інших різновидів оперного жсанру, стає рівноправною одиницею, зберігаючи $i$ зміцнюючи цей статус аж до сьогодні. Найбільш показовими рисами камернізаціі оперного жанру можна назвати його психологічну спрямованість у поєднанні з прагненням передати складний та суперечливий внутрішній світ героїв оперного твору. Найчастіше композитори створюють концепцію 
рефлексуючої людини і відчуття протистояння особистості навколишнього світу.

Ключові слова: опера, жанр, камерна опера, камернізація, драматургічний зміст, «нова драма».

Актуальность избранной темы объясняется тем, что на рубеже XIX-XX веков, а также в первые годы XX столетия многие исследователи говорили о кризисе оперного искусства, более того, существовало мнение, что падение интереса к жанру оперы со стороны слушательской аудитории можно объяснить осложнением музыкально-драматического содержания оперных произведений. Между тем именно в связи с происходящими процессами в оперном искусстве и стремлением выйти их кризисной ситуации на рубеже XIX-XX веков происходит процесс интенсивного жанрового обновления, подтверждением чего служат десятки оперных произведений, появившиеся в этот период в творчестве представителей различных национальных школ, причем эти произведения сегодня рассматриваются как классические образцы оперного жанра в XX веке.

В целом XX век стал периодом, когда сушественно пересматриваются представления об оперном жанре и его границах. Размышления на эту тему приводят к тому, что некоторые исследователи оперного искусства предлагают отказаться от термина «опера» и заменить его более объемным понятием «музыкального театра». Объясняется это тем, что значительная часть оперных произведений, написанных в $\mathrm{XX}$ веке, не отвечает тем жанровым критериям, которые на протяжении продолжительного времени применялись к опере.

Целью статьи является исследование генезиса камерной оперы на пути формирования ее типологических признаков и возникновения различных жанровых модификаций. Научная новизна обусловлена выявлением и обоснованием типологических черт, характерных особенностей жанровой сферы камерной оперы. Методология. В статье применяется обновленный аналитический подход в изучении европейских камерных опер, на основании которого становится возможным определять жанровые атрибуты и характерные особенности композиторского стилистического комплекса.

Обзор литературы по избранной проблематике. Все музыковедческие исследования, в которых в той или иной степени затрагивается явление камерной оперы, можно условно разделить на три группы. К первой группе можно отнести исследования А. Гозенпуда, посвященные изучению истории русского и советского оперного театра, и 
очерки по драматургии оперы XX века Б. Ярустовского. В этих работах методично рассматриваются определенные исторические периоды в развитии оперного жанра и наряду с изучением многоактных опер рассматриваются образцы опер малой формы. Вторую группу исследований составляют монографические работы о творчестве композиторов, обращающихся в своем творчестве к оперному жанру и в том числе и камерной опере. Среди подобных исследований следует назвать работы, посвященные изучению творчества Б. Бартока, Б. Бриттена, 3. Кодаи, П. Хиндемита, И. Стравинского и мн. др. И, наконец, третья группа исследований включает в себя весьма небольшой ряд исследований, которые в качестве предмета избирают именно оперу малой формы или камерную оперу. К таким работам следует отнести исследования Р. Розенберг, А. Селицкого, М. Басок, некоторых других.

Изложение основного материала. Динамическое взаимодействие оперного искусства со смежными жанрами и процесс проникновения в оперу элементов, характерных для иных жанровых форм, является одним из наиболее общих признаков развития музыки в XX веке, что в свою очередь приводит к возникновению оперных произведений смешанного типа. Так, опера сближается с ораторией, кантатой, в ней используются элементы пантомимы, различных театрально-сценических форм, кинематографа. В процессе более чем четырехвекового развития оперы, сложилось множество жанровых типов и исторических моделей оперы, разновидностей, так или иначе (иногда косвенно) отражающих специфику этого вида искусства, различных жанровых обозначений.

Важной составляющей эволюции камерной оперы, или как ее иногда определяют - оперы малой формы, становится обогашение ее музыкально-драматургических принципов посредством привлечения приемов, характерных для иных театральных и музыкальных жанров. Такая тенденция существенно обновляет и изменяет саму природу оперы, что и позволяет нам говорить об обособлении жанра камерной оперы. В свою очередь, камерная опера представляет собой неоднородное явление, в котором можно выделить несколько направлений, что позволяет производить деление в рамках этой жанровой разновидности.

Камерная опера во многих музыковедческих исследования именуется оперой малой формы или малой оперой, тем самым разграничивая явления большой и малой формы. Хотя наряду с подобным 
обозначением не меньшее распространение имеет обозначение опер, принадлежащих к малой жанровой разновидности, как камерных. Термин «камерный» оказывается уместным для отражения специфических черт небольшого оперного произведения, где камерность имеет равное отношение как к ограниченным пространственно-временным параметрам произведения, лаконичному сценическому воплощению с отказом от зрелищности и масштабности, характерной для многоактной разновидности оперы, так и к количеству исполнителей - инструменталистов и вокалистов. Последнее может служить подтверждением обоснованности применения именно данного термина - камерная опера. Иными словами, термин камерная опера может быть использован как универсальный, хотя и требует некоторых уточнений.

На пути жанрового становления камерной оперы особую значимость в приобретении ею ряда специфических черт, которые позволили автономизироваться этому явлению, имеют такие жанровые оперные разновидности как «мадригальная» опера, буффонная опера-интермедия, речитативно-декламационная опера, опера-диалог, опера-монолог. Общие выразительные средства и исполнительские приемы возникают между этими разновидностями и образуют своего рода «интертекст», который служит основанием для определения «своего» стиля в данной жанровой области. Отметим, что, как указывает С. Осадчая, «духовно-смысловой центр оперы не может находиться вне сюжета, действия, конфликта, характера героев, вне жанрового наклонения драматического целого» $[7,11]$.

Примечательно, что формирование музыкально-стилевых и стилистических свойств камерной оперы происходит в непосредственной связи между ее драматическим, поэтическим и театрально-сценическим уровнями. Иными словами, взаимодействие указанных уровней и возникающий как следствие феномен камерной оперы представляет типичный для этой жанровой формы художественный синтез и должен оцениваться в связи с ним. В данном контексте чрезвычайную важность приобретает связь со словесным (поэтическим) уровнем, который следует рассматривать и как структурно-композиционное, и как содержательное начало жанровой формы. Однако, как указывает О. Лисовая, «важнее всего связь этой жанровой разновидности с трагедийной эстетикой, что и ведет к формированию таких ее психологически углубленных разновидностей, как моноопера и дуоопера, в их явном тяготении к друг другу» $[6,69]$. 
Исходя из сказанного, можно прийти в выводу, что с конца XIX столетия камерная опера становится полноценной жанровой единицей, актуальность и востребованность которой не только сохраняется, но и усиливается в музыкальной культуре сегодняшнего дня. Важной стороной камерной оперы становится тенденция психологизации образов, стремление к точному и тонкому воплощению внутреннего мира героев, сложных, противоречивых, а порой и аномальных их состояний. Причем на этом пути происходит максимальное сближение названных тенденций с индивидуальными композиторскими установками, «обостренное ощущение противостояния личности окружающему миру, концепция рефлектирующего человека, находящегося в сфере духовного и душевного отчуждения (отторжения) от самого себя и непонятной действительности» [5, 104-105].

O. Комарницкая в работе «Русская опера XIX - начала XXI веков. Проблемы жанра, драматургии, композиции», останавливаясь на камерной опере обозначенного исторического периода, отмечает, что «в камерных сочинениях также - в той или иной степени - действуют принципы поэтических родов искусства: драмы - в операх «Моцарт и Сальери», «Скупой рыцарь», «Алеко», «Боярыня Вера Шелога», «Пир во время чумы», лирики и драмы - в опере «Франческа да Римини». «Иоланта» является, по-видимому, единственным образцом лирической оперы в русском искусстве классического периода в ее моножанровом воплощении» [5, 105].

К уже обозначенным особенностям камерной оперы следует добавить еще ряд особенностей, отмеченных Б. Ярустовским. К ним следует отнести возросшее в камерной опере значение оркестра, тесную связь в логике и приемах развития оперных форм и чисто инструментальных, возросшую роль тембровой драматургии и увеличение роли разработочности в оркестровой ткани. Говоря о выразительных возможностях камерной оперы, приведем высказывание Б. Бриттена, который с особым вниманием относился к этому жанру. Камерная опера представлялась ему «более гибкой для выражения сокровенных чувств. Она дает возможность заострить внимание на психологии человека» $[3,63]$. Подобный интерес к внутреннему миру человека является свойством, характерным не только для оперы, написанной для камерного состава исполнителей и ограниченного количества действующих лиц. В равной степени это свойство типично для многих других оперных произведений, вполне традиционных с точки зрения использованных драматургических, музыкально-выразитель- 
ных средств и с точки зрения исполнительского состава («Воццек» А. Берга, «Катерина Измайлова» Д. Шостаковича и др.).

Авторы музыковедческих работ, в которых анализируется оперное творчество отдельных композиторов, либо оперы, в которых ясно ощущается тенденция камернизации, зачастую сосредоточивают свое исследовательское внимание на изучении драматургических и формообразующих принципов произведения, не давая при этом обобщенных жанровых определений. В большинстве случаев авторы монографий сосредоточиваются на заголовках и подзаголовках, данных самим композитором, конечно, углубляя при этом изучение культурного контекста, оказавшего влияние на создание конкретного произведения.

Если традиционная система единиц деления оперы не может быть вполне приемлемой для определения специфики современной многоактной оперы, в случае с камерной общепринятая в музыковедческих исследованиях система оказывается недостаточной, а в отдельных случаях несостоятельной. Даже содержательный уровень оперного произведения перестает быть определяющим моментом драматургии и формы, как это было в классической многоактной опере XVIII-XIX веков и хотя бы отчасти сохранялось в современной многоактной опере.

Следовательно, основываясь на проведенном анализе, можно сделать вывод, что жанровый подзаголовок в камерной опере перестает отражать специфические черты драматургии и формообразования. В свою очередь указанный жанровый подзаголовок перестает служить ориентиром в анализе того или иного произведения, как это наблюдалось в случае с традиционной многоактной оперой, а сравнение по признакам общности или отличия и отнесение анализируемой оперы к той или иной группе аналогичных произведений остается необходимым моментом.

В каждой из обозначенных разновидностей камерной оперы действуют свои индивидуальные законы, которые в той или иной степени присутствуют в оперных произведениях, однако практически в каждом заметном проявлении оперного жанра можно обнаружить уникальные черты, позволяющие говорить о своеобразии его концепции. Художественная тенденция камерной оперы как «искусства состояния» связана с процессом психологического обоснования, внутренней мотивации поступков персонажей - в отличие от крупномасштабных сочинений, в которых психологические проявления 
героев олицетворяют отражение предшествующего внешне-сценического действия и проецируют в свою очередь развертывание будущих сюжетных событий. Благодаря этому, как отмечает О. Комарницкая, можно говорить о возникновении особой внутреннеконфликтной драматургии, опосредованной через «коллизии главного действующего лица (выступающего чаще всего в роли единственного героя, в котором сосредоточено действенное начало, - Сальери, Барон, Алеко, Вальсингам)» [5, 104].

В связи с этим очень важными оказываются мысли М. Бахтина о художественном процессе, художественном акте. Он указывал, что художественный акт «движется не в пустоте, а в напряженной ценностной атмосфере ответственного взаимоопределения» $[1,26]$. Далее М. Бахтин указывает, что хотя художественное произведение ограничено пространственно и временно, вытесняя при этом из «занятого ею пространства все остальное», но «живо и значимо» художественное произведение при этом становится только «в напряженном и активном взаимоопределении с опознанной и поступком оцененной действительностью (курсив наш - A. H.)» [1, с. 26].

При этом, обсуждая процесс возникновения содержания художественного произведения, М. Бахтин приходит к заключению, что появление его есть следствием действительности познания и этического поступка, которая входит «в своей опознанности и оцененности в эстетический объект» и подвергается при этом «конкретному, интуитивному объединению, индивидуации, конкретизации, изоляции и завершению, то есть всестороннему художественному оформлению с помощью определенного материала» [1, 32]. Эти мысли М. Бахтина, чрезвычайно важные в процессе изучения любого художественного явления и его содержания, в нашем случае приобретают особое значение, так как, словами М. Бахтина, «содержание есть необходимый конститутивный момент эстетического объекта, ему коррелятивна художественная форма, вне этой корреляции не имеющая вообще никакого смысла» [1, 32].

Примечательно, что зачастую те действующие силы и обстоятельства, которые инициировали драматические (а порой трагедийные) перипетии сюжета камерной оперы, являются некоей событийной канвой и остаются за пределами произведения, то есть существует некий конфликт за рамками произведения, разрешение или обсуждение которого и разворачивается в пределах композиционных границ конкретного образца камерной оперы. 
В целом художественно-эстетическая тенденция камернизации оперного жанра является результатом стремления композиторов максимально точно передать внутреннее психологическое состояние персонажей оперы, попытаться обосновать и мотивировать их поступки. В этом можно наблюдать наиболее показательное отличие от крупномасштабных оперных сочинений, в которых психологические состояния героев отражают предшествующее оперно-сценическое действие и в значительной степени определяют последующее развертывание оперного текста.

Иными словами, в многоактных операх любые психологические проявления подготовлены и объясняются предыдущим музыкальносценическим материалом и, в свою очередь, определяют дальнейшее развитие произведения. В камерной опере словно производится оттиск, слепок психологического состояния героя в данный момент времени. Это объясняет освоение оперой нового для нее типа драматургии, который определяется И. Чистюхиным в книге «О драме и драматургии» как внутреннеконфликтная драматургия или внутренний вид конфликта [8, 62].

Исследователь характеризует этот тип драматургического конфликта как конфликт внутри человека, конфликт самого с собой. «Например, между разумом и чувством; долгом и совестью; желанием и моралью; сознанием и подсознанием; личностью и индивидуальностью; сущностью и существованием и т. д.» $[8,62]$. Поэтому в театрально-сценической реализации передача внутреннего вида конфликта чаще всего происходит через коллизии главного действующего лица, выступающего в роли единственного героя, в котором сосредоточено действенное начало.

Это подтверждается продолжительным рядом оперных сочинений, в которых мы можем наблюдать либо предельно сокращенный состав персонажей, либо сведение состава к одному действующему лицу. В целом можно сказать, что, камерного типа оперного произведения характерен принцип воплощения «внутреннего человека», по М. Бахтину, с присущим данному типу полифоническим сопоставлением «контрастных неслиянных голосов». Это коренным образом отличает камерную оперу от многоактной, так как в последней присутствует разнообразие нравственно-философских точек зрения, обусловленное, в первую очередь, большим количеством действующих лиц. Особо отметим позицию М. Бахтина, который указывает, что постижение «глубин души человеческой» невозможно на пути «ов- 
нешняюще-завершающего» исследования, так как «..овладеть внутренним человеком, увидеть и понять его нельзя, делая его объектом безучастного нейтрального анализа, нельзя овладеть им и путем слияния с ним, вчувствованием в него. Нет, к нему можно подойти и его можно раскрыть - точнее, заставить его самого раскрыться - лишь путем общения с ним, диалогически» (курсив наш - A. H.) [2, 293].

Общие драматургические принципы камерной оперы связаны, с одной стороны, с концентрацией сюжета вокруг одной линии действия, что ярко контрастирует с многоплановыми сюжетными линиями, которые развиваются в большой опере. С другой стороны, в камерной опере наблюдается максимальная эмоционально-психологическая насыщенность, которая порой превосходит по своему накалу образцы многоактной оперы. Основой вокальной речи персонажей становится декламационный или речитативно-ариозный стиль, обладающий огромными возможностями в воплощении эмоционально-рефлексирующих состояний человеческой души.

Изучая принципы драматургического строения в камерных оперных сочинениях, следует отметить, что камерная опера вовлекает в свой круг художественно-выразительных и образно-смысловых средств ряд приемов и качеств, принадлежащих смежным художественным явлениям. Примером может служить традиционное для оперы сочетание драмы и музыки, однако драма предстает в несколько обновленном виде, а именно в виде использования принципов «новой драмы». Исследования последних лет, в которых затрагивается явление «новой драмы», указывают на особое понимание конфликта и его обновленную трактовку, в которой формируется новый пространственно-временной континуум, отличающийся двуслойностью и двунаправленностью. События произведений «происходят в настоящем, но проецируются на всю человеческую жизнь» $[4,156]$.

Выводы. Таким образом, с конца XIX века, камерная опера приобретает самостоятельность, отделяясь от иных разновидностей оперного жанра, становится равноправной единицей, сохраняя и упрочивая этот статус вплоть до сегодняшних дней. Наиболее показательными чертами камернизации оперного жанра можно назвать ее психологическую направленность со стремлением передать сложный и противоречивый внутренний мир героев оперного произведения. Зачастую композиторы создают концепцию рефлексирующего человека и ощущение противостояния личности окружающему миру. 
Исходя из этого, выявляются свойства, характеризующие новую драму, и через нее объясняющие процессы, происходящие в камерной опере. Так, для произведений этого типа характерно расширение границ времени и пространства, что приводит к дискретной, разорванной композиции в произведениях, бытовая сторона может присутствовать в произведениях, но она отодвинута на второй план и является лишь обрамлением действия. Финальные сцены, как правило, не вносят ясности в представленное действо, а скорее остаются открытым текстом, многоточием. Очень показательным и важным свойством, характеризующим как произведения «новой драмы», так и камерные оперы, становится ослабление единства пространства и времени в сочетании с усилением единства действия. В «новой драме» усиление единства действия осуществляется за счет сокращения количества действующих лиц, которое сводится порой к одному главному герою (рассказчик в монодраме).

Это может быть соотнесено с идентичными процессами в камерной опере, в которой также количество задействованных в опере персонажей может быть сведено к одному действующему лицу (как в моноопере). Сами же события, разворачивающиеся в «новой драме» или камерной опере, представляют собой ряд жизненных ситуация, фрагментов, словно вырванных из бесконечной череды событий, что очень роднит эти два явления. В целом общую устремленность драматургического решения можно представить как самое эмоционально напряженное высказывание, как «крик души», затрагивающий не только лично героя произведения, но и наиболее болезненные стороны жизни социума.

\section{СПИСОК ЛИТЕРАТУРЫ}

1. Бахтин М. Проблема содержания, материала и формы в словесном художественном творчестве. Бахтин М. Вопросы литературы и эстетики. Исследования разных лет. М. : Художественная литература, 1975. С. 6-72.

2. Бахтин М. Проблемы поэтики Достоевского. М. Бахтин. Собрание сочинений: в семи томах. М. : Руские словари, 2000. Т. 2. С. 5-176.

3. Говорит Бенджамин Бриттен. Советская музыка, 1965. № 3. С. 63-64.

4. Екабсонс А. Принципы воссоздания локально-темпорального континуума в «Новой драме» рубежа XX-XXI века. Молодой ученый. 2012. № 7. C. $156-158$.

5. Комарницкая О. Русская опера XIX - начала XXI веков. Проблемы жанра, драматургии, композиции : дис. ... докт. искусствоведения, спец. : 17.00.02 - музыкальное искусство. М., 2011. 757 с. 
6. Лисовая О. Программность как жанровая парадигма камерной вокальной музыки: к проблеме исполнительского понимания : дис. ... канд. искусствоведения, спец. : 17.00.03 - музыкальное искусство. Одесса, 2009. 176 с.

7. Осадчая С. Духовно-религиозные предпосылки реформы европейской оперы XIX-XX вв. Музичне мистецтво і культура : науковий вісник Одеської національної музичної академії ім. А. В. Нежданової. Одеса : Астропринт, 2013. Вип. 18. С. 10-19.

8. Чистюхин И. Н. О драме и доаматургии. М. : Высшая школа, 2002. 293 с.

\section{REFERENCES}

1. Bakhtin, M. (1975) The problem of content, material and form in the verbal art. Bakhtin M. Questions of literature and aesthetics. Studies of different years. M.: Fiction. [in Russian].

2. Bakhtin, M. (2000) Problems of Dostoevsky's Poetics. M. Bakhtin. Collected Works in Seven Volumes. M.: Russian Dictionaries. Vol. 2. [in Russian].

3. Says Benjamin Britten. (1965) Soviet music. Vol. 3. [in Russian].

4. Jekabsons, A. (2012) Principles of recreation of the local-temporal continuum in the «New drama» of the turn of the XX-XXI centuries. Young scientist. № 7. [in Russian].

5. Komarnitskaya, O. (2011) Russian Opera XIX - early XXI centuries. Problems of the genre, drama, composition: diss.... Doctor of Art History, specialty: 17.00.02 - musical art. M. [in Russian].

6. Lisovaya, O. (2009) Programming as a genre paradigm of chamber vocal music: on the problem of performing understanding: dis.... Cand. art history, specialty: 17.00.03: Musical art. Odessa. [in Russian].

7. Osadchaya, S. (2013) The spiritual and religious background of the reform of the European opera of the XIX - XX centuries. Musical art and culture. Odessa: Astroprint. Vol. 18. [in Russian].

8. Chistyukhin I. N. About drama and dramaturgy. M. : High school. [In Russian].

Стаття надійшла до редакції 13.09.2017 